\title{
DESEMPENHO E UNIFORMIDADE DA DISTRIBUIÇÃO DE ÁGUA DE UM PIVÔ CENTRAL ${ }^{\prime}$
}

\author{
PERFORMANCE OF A CENTER PIVOT IRRIGATION SYSTEM AND \\ IRRIGATION DISTRIBUTION UNIFORMITY
}

\author{
Vitor Hugo Cainelli ${ }^{2}$ Adroaldo Dias Robaina ${ }^{3}$ Reimar Carlesso $^{4}$ Carlos Renan Denardin Dotto ${ }^{5}$
}

\section{RESUMO}

O objetivo deste experimento foi avaliar as caracteristicas de desempenho de um equipamento de irrigação pivô central, de baixa pressão, bem como determinar a uniformidade de distribuição de água, tanto abaixo como acima da superficie do solo. Para a avaliação do desempenho do sistema utilizaram-se os coeficientes de uniformidade de Christiansen (CUC) e de distribuição (CUD). calculados a partir de dados da precipitação dos aspersores. O pivô central foi ensaiado nas velocidades de $25 \%$, $50 \%, 75 \%$ e $100 \%$ da velocidade máxima de deslocamento do equipamento. Utilizou-se quatro linhas de coletores, uniformemente espaçados. Os valores encontrados do CUC e o CUD foram superiores ao mínimo recomendado para a cultura do milho, confirmando o bom desempenho do pivó central. Em todas as profundidades do solo estudadas os coeficientes de uniformidade foram superiores aos obtidos acima do solo, ocorrendo um aumento nos valores dos coeficientes de uniformidade abaixo da superficie do solo com o tempo.

Palavras-chave: irrigação, pivô central, uniformidade de distribuição.

\section{SUMMARY}

The objective of this work was to evaluate some characteristics of a center pivot irrigation system equipament, as well as to determine the water distribuition uniformity, under and over the soil surface. The Christiansen uniformity coefficient (CUC) and distitibuition (CUD) were used to evaluate the system.

\begin{abstract}
A low pressure center pivot was tested in four different speeds. $25 \%, 50 \%, 75 \%$ and $100 \%$ of the timer sensor, and in four collectors lines spaced. Results indicated that both coeficients presented good performance. The values of CUC and CUD were above the minimum recommended for na irrigated corn field. The uniformity coefficients in all depths of the soil were higher than the above the soil surface. Howerer, the uniformity under soil surface increased with the time in all depths.
\end{abstract}

Key words: irrigation, center pivot, uniformity distribuition

\section{INTRODUÇÃO}

Nos últimos anos tem aumentado a utilização de equipamentos de irrigação, sendo observado projetos implantados sem a utilização de critérios técnicos mínimos aceitáveis para uma aplicação uniforme da irrigação. Os principais problemas normalmente encontrados são equipamentos desativados por falta de água em função de sistemas de bombeamento mal dimensionados que não fornecem a vazão e a pressão suficientes para um bom desempenho do sistema, ou até mesmo, problemas de cavitação da bomba. Encontra-se também equipamentos que aplicam volumes de água diferentes dos realmente necessários para as culturas, ocasionando, frequiente-

\footnotetext{
${ }^{1}$ Parte da Dissertação de Mestrado apresentada pelo primeiro autor, em 19.08.96. ao Curso de Pós-graduação em Engenharia Agrícola Universidade Federal de Santa Maria (UFSM), Área de Irrigaçăo e Drenagem.

${ }^{2}$ Engenheiro Operacional Civil, aluno do curso de Pós-graduação em Engenharia Agrícola da UFSM ${ }^{3}$ Engenheiro Agrônomo, Dr., Professor Titular do Departamento de Engenharia Rural, UFSM, 971 19-900 - Santa Maria, RS. Autor para
correspondência.

${ }^{4}$ Engenheiro Agrônomo, PhD., Professor Titular do Departamento de Engenharia Rural, UFSM.

${ }^{5}$ Engenheiro Agrônomo, McS., Departamento de Engenharia Rural, UFSM. 
mente, grande desperdício de água e energia (SILVA \& PEREIRA, 1994).

O desenvolvimento de um manejo racional de irrigação deve ser precedido de um programa de ensaios dos equipamentos em operação. Os ensaios, que tem aplicações práticas imediatas, são realizados com a finalidade de aumentar o grau de aproximação entre os volumes que se deseja aplicar e aqueles realmente aplicados pelo equipamento em funcionamento, a identificação de componentes que devem ser reparados ou substituídos e a otimização do sistema de bombeamento, reduzindo o consumo de energia (COI.OMBO et al., 1988).

O planejamento racional de um sistema de irrigação requer o conhecimento da distribuição da água aplicada, uma vez que a baixa uniformidade de distribuição reduz a eficiência de aplicação o que pode conduzir a resultados insatisfatórios no manejo da irrigação (KINCAID \& HEERMANN, 1970).

$O$ objetivo deste trabalho foi avaliar as características de desempenho do pivô central e determinar a uniformidade de distribuição de água acima e abaixo da superfície do solo.

\section{MATERIAIS E MÉTODOS}

O estudo foi conduzido na Fazenda da Lagoa, de propriedade do Sr. João Zielmann localizada no município de Fortaleza dos Valos - RS. $O$ solo do local foi classificado como Latossolo Vermelho Escuro Distrófico, textura argilosa, relevo ondulado e substrato basalto (Oxisol), pertencente à unidade de mapeamento Passo Fundo (BRASIL, 1973).

O sistema de irrigação utilizado foi do tipo pivô central, de fabricação da empresa Fockink Equipamentos Elétricos Ltda, modelo AF-S2-BP-06198. operando em baixa pressão, com seis torres, comprimento total da linha lateral de $323,2 \mathrm{~m}$, altura de $3 \mathrm{~m}$, dotado de difusores e reguladores de pressão marca Seninger.

A vazão do pivô central foi determinada com um medidor digital marca Motorola HT 600, instalado no tubo de subida da torre central.

A pressão na entrada da bomba foi determinada através de um vacuômetro com coluna de mercúrio ligado a tubulação de sucção e a pressão de saída da bomba foi medida com um manômetro tipo Bourdon. A altura manométrica do sistema de bombeamento foi obtida pela soma de pressão na entrada e de pressão na saída da bomba.

$O$ valor do NPSH (net positive suction head) requerido para a instalação em estudo, foi calculado segundo as normas da KSB-Bombas
Hidráulicas S.A. e o NPSH disponível foi calculado segundo SILVESTRE (1979).

0 tempo necessário para uma volta completa do pivô central em estudo foi calculado a partir dos valores obtidos em ensaio de campo e informados pelo projeto.

A velocidade do pivô ceritral foi determinada medindo-se uma distância de $20 \mathrm{~m}$ na trajetória da última torre dividida pelo tempo do percurso. Este ensaio foi efetuado para diferentes regulagens do relé percentual e em diferentes posições do percurso do equipamento, sendo utilizados três repetições. Com estes dados determinou-se o tempo por volta para cada regulagem do relé percentual.

A lâmina média aplicada foi calculada em função da vazão do pivô, do tempo por volta e da área irrigada, para as quatro regulagens do relé percentual (BERNARDO, 1989).

A distribuição da água na superfície do solo foi avaliada em quatro velocidades de deslocamento (25\%, 50\%, 75\% e $100 \%$ da regulagem do relé percentual), utilizando-se os valores obtidos de três repetições para cada velocidade, baseada na metodologia proposta por MERRIAN \& KELLER (1979).

Foram instalados 54 coletores, nivelados e distantes da superfície do solo em $30 \mathrm{~cm}$, em quatro raios (norte, sul, leste e oeste). Os coletores foram numerados, em ordem crescente, a partir do centro do pivô e eqüidistantes entre si em $6 \mathrm{~m}$ e o fator de ponderação considerado foi o número de ordem do coletor.

A determinação da distribuição da água abaixo da superfície do solo foi realizada utilizando-se amostras de solo, coletadas dentro de um círculo de $30 \mathrm{~cm}$ de raio ao redor do coletor, nas camadas de 0 $15,16-40,41-70,71-100$ e $101-130 \mathrm{~cm}$. As amostras de solo foram coletadas antes da irrigação e em tempos de zero, seis, doze, vinte e quatro e trinta e seis horas após a passagem do equipamento pela linha de coletores. O conteúdo de água das amostras foi determinado pela média de três amostras retiradas em cada profundidade, nos coletores de número par, utilizando-se o método gravimétrico e transformadas em lâminas armazenadas no solo. Essa determinação foi realizada apenas para a regulagem de $25 \%$ do relé percentual, na linha lateral de raio norte.

A determinação do coeficiente de uniformidade (CUC), foi realizada utilizando o método proposto por HEERMANN \& HEIN (1968), e o coeficiente de uniformidade de distribuição (CUD) foi determinado segundo a metodologia apresentada por DAVIS (1966). 


\section{RESULTADOS E DISCUSSÃO}

Os valores encontrados na medição da vazão variaram entre 58 a $601 . \mathrm{s}^{-1}$, o que corresponde a $209-215 m^{3} \cdot h^{-1}$, com média de $212 m^{3} \cdot h^{-1}$. O valor médio difere do valor de projeto $\left(206 \mathrm{~m}^{3} \cdot \mathrm{h}^{-1}\right) \mathrm{em}$ torno de $4 \%$.

A altura manométrica de projeto é de $106 \mathrm{mca}$. Segundo as leituras efetuadas a campo a pressão medida na sucção foi de 4,73 m.c.a., a pressão na saída da bomba de 100 m.c.a., o que determinou uma altura manométrica de aproximadamente 105 m.c.a. A diferença entre as alturas manométricas de projeto e medida diferiram em menos de 1\%. Esses resultados podem ser considerados normais, uma vez que existe uma certa imprecisão nas leituras feitas nos manômetros devido a oscilação do ponteiro indicador e outros erros como os descritos por GILL (1984).

O critério de verificação das condições de uma instalação de bombeamento, segundo a maioria dos autores, estabelece que uma relação entre o NPSH disponivel e o NPSH requerido, deve ser maior ou no mínimo igual a 1,15. Neste trabalho, esta relação apresentou um valor de 1,92, satisfazendo, com folga, o critério de verificação adotado, uma vez que o NPSH requerido apresentou o valor de $2,82 \mathrm{~m}$.c. a. e o NPSH disponível o valor de $5,42 \mathrm{mca}$.

Com relação a velocidade do pivô central. os valores calculados a partir das determinações da velocidade de deslocamento da última torre, nas diferentes regulagens do relé percentual, a partir de ensaios no campo, foram sempre superiores aos valores indicados pelo projeto, conforme pode ser visto na Tabela 1. Os valores dos desvios relativos das velocidades observadas nos ensaios em relação as do projeto variaram, aproximadamente, entre 9 e $10 \%$.

$$
\text { A Tabela } 1
$$

apresenta os valores do tempo necessário para uma volta completa do pivô central em estudo. SAAD et al. (1987), analisando sete equipamentos de irrigação do tipo pivô central, encontraram desvios relativos variando entre 3 e $22 \%$ das mesmas variáveis estudadas, sendo os tempos necessários para o pivô central completar uma volta sempre inferiores aos valores indicados pelo projeto, variando os respectivos desvios. entre 7,72 e 8,99, tendo como valor médio de aproximadamente $8,62 \%$.

A lâmina média de água aplicada depende diretamente da vazão do pivô, do tempo por volta e da área irrigada. Os valores calculados, a partir de dados de ensaio da vazão e do tempo por volta, da lâmina média aplicada pelo pivô central foram muito próximos aos valores indicados pelo projeto, conforme a Tabela 1. Os valores dos desvios relativos da lâmina média aplicada calculadas e os de projeto variaram entre 1,67 e $2,81 \%$, tendo como valor médio $2,50 \%$. Esses resultados são reflexos diretos da velocidade de deslocamento observada nos ensaios, porque os tempos por volta foram sempre inferiores aos do projeto, o que implicaria uma lâmina aplicada menor, mas que teria desvios da ordem dos desvios encontrados para a o tempo por volta. Por outro lado, quando se associou os valores dos tempos por volta reais, obtidos em ensaios de campo, aos valores da vazão e da área irrigada, os desvios da lâmina realmente aplicada são menores devido ao desvio da vazão real em relação a do projeto em sentido inverso do tempo de deslocamento, compensando a diferença. Em ensaios realizados em sete pivôs centrais SAAD et al. (1987), encontraram desvios entre a lâmina média aplicada real e a do projeto variando entre 5 e $15 \%$, o que mostra que os resultados encontrados nesse trabalho foram inferiores ao menor desvio encontrado por aqueles pesquisadores.

Os resultados obtidos do CUC foram superiores a $86 \%$ em qualquer raio (Tabela 2). Em todas as situações mantiveram valores acima do recomendado para a cultura do milho, confirmando a recomendação de MERRIAN \& KELLER, (1979), BERNARDO (1989) e BENAMI \& OFEN (1993). A média dos quatro raios foi superior a $90 \%$, o que

Tabela 1 - Velocidade da última torre de um pivô central obtida em uma distância de 20 metros, tempo por volta obtido em um percurso de 1851,65 metros e lâmina média de água aplicada com vazão de $212 \mathrm{~m}^{3} / \mathrm{h}$, calculados através de determinações à campo e obtidos do projeto original sob diferentes velocidades de deslocamento (regulagem do relé percentual), com

\begin{tabular}{|c|c|c|c|c|c|c|c|c|c|}
\hline \multirow{2}{*}{$\begin{array}{l}\text { Relé } \\
(\%)\end{array}$} & \multicolumn{3}{|c|}{ Velocidade $\left(\mathrm{m} \cdot \mathrm{h}^{-1}\right)$} & \multicolumn{3}{|c|}{ Tempo por volta (h) } & \multicolumn{3}{|c|}{ Lâmina aplicada (mm) } \\
\hline & Medida & Projeto & Desvio\% & Medida & Projeto & Desvio\% & Calculada & Projeto & Desvio\% \\
\hline 100 & 332,4 & 305,6 & 8,77 & 5.57 & 6,00 & -7.72 & 3.60 & 3,66 & $-1,67$ \\
\hline 75 & 252,1 & 229,2 & 9,99 & 7.34 & 8,00 & $-8,99$ & 4,75 & 4,88 & $-2,74$ \\
\hline 50 & 168,1 & 152,8 & 10.01 & 11.02 & 12,00 & $-8,89$ & 7,12 & 7.32 & $-2,81$ \\
\hline 25 & 84,0 & 76,4 & 9,95 & 22,04 & 24,00 & $-8,89$ & 14,24 & 14.64 & $-2,81$ \\
\hline
\end{tabular}

Ciência Rural, v. 28, n. 1, 1998. 
permite, segundo BERNARDO (1989), afirmar que o equipamento apresenta uma boa uniformidade de aplicação de água na superfície do solo e/ou das plantas. Um valor do CUC de $80 \%$ é, segundo OLITTA (1977) e BERNARDO (1989), o mínimo aceitável para uma boa uniformidade de aplicação.

Tabela 2 - Valores do Coeficiente de Uniformidade de Christiansen (CUC) e Coeficiente de Uniformidade de Distribuição (CUD) acima da superfície do solo obtidos para os diferentes raios e nas diferentes regulagens do relé percentual e velocidade média do vento.

\begin{tabular}{lcccccc}
$\begin{array}{l}\text { Relé } \\
(\%)\end{array}$ & $\begin{array}{r}\text { Raio } \\
(\%)\end{array}$ & $\begin{array}{r}\text { Raio } \\
(\%)\end{array}$ & $\begin{array}{r}\text { Raio } \\
(\%)\end{array}$ & $\begin{array}{r}\text { Raio } \\
(\%)\end{array}$ & $\begin{array}{c}\text { Média } \\
(\%)\end{array}$ & $\begin{array}{c}\text { Vel. } \\
\text { Vento } \\
(\mathrm{m} / \mathrm{s})\end{array}$ \\
\hline 100 & 91,9 & 86,7 & 91,4 & 89,9 & 90,0 & 7,7 \\
75 & 91,0 & 90,0 & 90,4 & 88,5 & 90,0 & 3,1 \\
50 & 89,7 & 89,9 & 88,5 & 91,7 & 90,0 & 2,1 \\
25 & 89,2 & 91,3 & 90,6 & 93,3 & 91,1 & 1,4 \\
Média & 90.3 & 89,5 & 90,2 & 90,9 & 90,3 & $-\cdots$ \\
& & & & & & \\
& & & & & & \\
100 & 85,4 & 81,1 & 83,2 & 83,9 & 83,4 & 7,7 \\
75 & 85,2 & 82,0 & 74,4 & 80,4 & 80,5 & 3,1 \\
50 & 86,2 & 77,3 & 82,1 & 87,3 & 83,2 & 2,1 \\
25 & 86,2 & 72,5 & 81,1 & 88,1 & 81,2 & 1,4 \\
Média & 85,8 & 78,2 & 80,2 & 84,9 & 82,2 & --- \\
& & & & & & \\
\hline
\end{tabular}

Quando se compara os valores do CUC obtidos em relação as diferentes velocidades de deslocamento, observa-se que foram semelhantes, indicando que o CUC independe do valor da velocidade de operação para a sua determinação. Resultados semelhantes também foram relatados por MERRIAN et al. (1973), BRIDI (1984) e COTRIM (1988).

Os valores do CUD foram sempre superiores a 70\%, valor que segundo BERNARDO (1989), é considerado como o mínimo aceitável. Os resultados médics do CUD foram superiores a $80 \%$ considerando-se a média dos quatro raios, mas inferiores aos valores do CUC. Este fato era esperado, uma vez que é inerente ao método de determinação do CUD que utiliza a média de $25 \%$ dos valores das menores lâminas da precipitação em relação a média geral. Os valores observados do CUD estão de acordo com SAAD et al. (1987).

Abaixo da superfície do solo (Tabela 3) pode-se observar que os valores médios dos coeficientes de uniformidade (CUC e CUD), em todas as profundidades, antes do início da passagem do equipa- mento pelo ponto de coleta de amostra foi superior a $96 \%$, e o valor médio desta determinação decresceu com o passar do tempo, sendo superado somente 36 horas após a passagem do equipamento.

Analisando-se os dados, pode-se observar que o valor médio do CUD em todas as profundidades, antes do início da passagem do equipamento pelo ponto de coleta de amostras, foi igual a $94,75 \%$ e o valor médio desta determinação decresceu com o passar do tempo, sendo superado 36 horas após a passagem do pivô central.

Os valores médios do CUC e do CUD, oscilaram entre 92 e $97 \%$ e entre 88 e $96 \%$, respectivamente. Os maiores valores dos coeficientes foram observados 36 horas após a passagem do equipamento e, estão de acordo com os resultados encontrados por PAIVA (1980) trabalhando com sistema de aspersão convencional e por REZENDE (1992) trabalhando com pivô central.

Na Figura 1 observa-se a variação da lâmina de água em torno da média, ao longo da lateral do pivô. A dispersão dos valores ao longo da lateral do pivô em relação a média é responsável pela desuniformidade da distribuição da água na área. Há evidencia

Tabela 3 - Valores do Coeficiente de Uniformidade de Christiansen (CUC) e Coeficiente de Uniformidade de Distribuição (CUD) abaixo da superfĩcie, em diferentes tempos após a passagem do equipamento com regulagem do relé percentual a $25 \%$ da velocidade máxima.

\begin{tabular}{lllllll}
$\begin{array}{l}\text { Prof. Antes da Zero } \\
\text { (cm) passagem }\end{array}$ & (h) & (h) & $\begin{array}{l}12 \\
\text { (h) }\end{array}$ & $\begin{array}{l}24 \\
\text { (h) }\end{array}$ & $\begin{array}{l}36 \\
\text { (h) }\end{array}$ \\
\hline
\end{tabular}

\section{CUC}

\begin{tabular}{|c|c|c|c|c|c|c|}
\hline $00-15$ & 98,68 & 91,78 & 88,73 & 94,04 & 94,63 & 98,15 \\
\hline $15-40$ & 97,58 & 91,11 & 95,18 & 95,44 & 96,26 & 96.60 \\
\hline-70 & 96,34 & 92,52 & 94,46 & 95,09 & 96,35 & 98,07 \\
\hline-100 & 94,93 & 89,50 & 94,74 & 93,76 & 95,27 & 97,21 \\
\hline $0-130$ & 93,65 & 92,72 & 93,36 & 93,53 & 93,77 & 96,21 \\
\hline édia & 96,24 & 91,53 & 93,27 & 94,37 & & 97,25 \\
\hline \multicolumn{7}{|c|}{ CUD } \\
\hline ) -15 & 97,84 & 88,57 & 86,17 & 93,00 & 93,44 & 97,28 \\
\hline-40 & 97,04 & 86,56 & 94,66 & 91,46 & 95,61 & 93,94 \\
\hline-70 & 94,20 & 89,67 & 92,87 & 92,74 & 85,25 & 97,47 \\
\hline-100 & 94,08 & 86,20 & 91,54 & 92,77 & 94,26 & 94,61 \\
\hline $0-130$ & 90,59 & 88,49 & 89,30 & & & \\
\hline lédia & 94,75 & 87,89 & 90,91 & 92,02 & 93,89 & $95,7^{7}$ \\
\hline
\end{tabular}

Ciência Rural, v. 28, n. 1, 1998. 
de problemas na distribuição da água ao longo da linha lateral. As lâminas abaixo da média nos últimos difusores foram causadas, provavelmente, por problemas de entupimento parcial ou mesmo total, uma vez que os mesmos foram desentupidos várias vezes durante a realização dos testes por acumulo de areia.

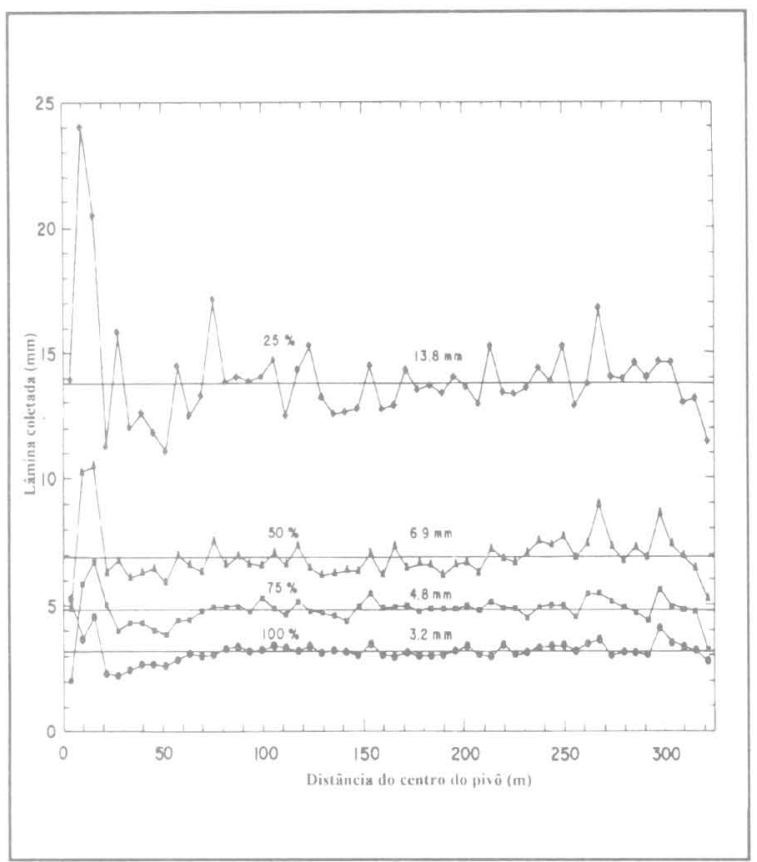

Figura 1 - Perfil da precipitação ao longo da linha lateral para o pivô central operando a diferentes velocidades de deslocamento

As lâminas acima da média verificadas nos primeiros difusores foram causadas, provavelmente, por problemas de funcionamento das válvulas reguladoras de pressão, uma vez que é nessa região que pode-se constatar a ocorrência das pressões mais elevadas ao longo da lateral.

Apesar dos altos coeficientes de uniformidade obtidos, os perfis de distribuição da água indicam que, os problemas verificados na distribuição podem prejudicar outras operações realizadas com o pivô estudado, que utilizam a água como veículo, tais como a fertirrigação em particular e a quimigação de uma forma geral, devido a variação das lâminas de água, principalmente nas posições mais distantes do ponto pivô.

\section{CONCLUSÕES}

O equipamento está operando de acordo com as condições descritas no projeto de dimensiona- mento. Os valores encontrados para os coeficientes de uniformidade, demonstram que o equipamento apresenta bom desempenho. Os valores dos coeficientes de uniformidade abaixo da superfície do solo apresentam, com o tempo, aumento em todas as profundidades $\mathrm{e}$ são superiores aos obtidos na superfície do solo.

\section{REFERÊNCIAS BIBLIOGRÁFICAS}

BENAMI, A., OFEN, A. Irrigation engineering: Sprinkler. trickler, surface irrigation. Principles, designe and agricultura pratices. Haifa: Agripo, 1993. 157 p

BERNARDO, S. Manual de Irrigação. 5. ed. Viçosa: Imprensa Universitária. 1989.596 p.

BRASIL. Ministério da Agricultura. Departamento de Pesquisa Agropecuária. Divisão de Pesquisa Pedológica. Levantamento de reconhecimento dos solos do Estado do Rio Grande do Sul. Recife DNPA. 1973. 431 p (Boletim Técnico, 30).

BRIDI, S. Análise de uniformidade de distribuição de água em sistema de irrigação por pivô central. Viçosa: Universidade Federal de Viçosa, 1984. 87 p. Dissertação (Mestrado) Universidade Federal de Viçosa, 1984.

COLOMBO, A., ZAGGO, S.P., ALBINO, J.A.S.. et al. Desempenho de sistema de irrigação por aspersão pivô central em Guaira, SP. In: CONGRESSO BRASILEIRO DE IRRIGAĊ̃̇O E DRENAGEM, 8, 1988, Florianópolis. Anais... Florianópolis Associação Brasileira de Irrigação e Drenagem. 1988 v. I. p 237-257

COTRIM. C.E. Análise de uniformidade de aplicação de água em sistema de irrigação do tipo pivô central de baixa pressão. Viçosa: Universidade Federal de Viçosa. 1988. 114 p. Dissertação (Mestrado) - Universidade Federal de Viçosa. 1988

DAVIS, J.R. Measuring water distribuition from sprinkler Tansacions of the ASAE. St. Joseph. n. 22, v. 5, p. 94-97. 1966

GILL, A.B. Power plant performance. London: Butterworth. 1984. 638 p.

HEERMANN, D.F., HEIN, P.R. Performance characteristics of self-propeled center-pivot sprinklers irrigation systems Tansactions of the ASAE. St. Joseph. n. 11, v. 1. p. 11-5. 1968

KINCAID, D.C., HEERMANN. D.F. Pressure distribuition on a center pivot sprinkler irrigation systems. Transactions of the ASAE, St. Joseph. n. 13. v. 11. p. 558. 1970

MERRIAN, J.L., KELLER. J. Farm irrigation system evaluation: a guide for management. Logan: Utah State University, 1979. $271 \mathrm{p}$.

MERRIAN, J.L., KELLER, J., ALFARO. J. Irrigation; system avaluation and improvement. Logan: Utah State University. 1973. n.p.

OLITTA, A.F.L. Os métodos de irrigacão. São Paulo: Nobel. 1977. $267 \mathrm{p}$. 
PAIVA, J.B.D. de. Uniformidade de aplicação de água, abaixo da superficie do solo, utilizando irrigação por aspersão. São Carlos, 1980.333 p. Dissertação (Mestrado em Hidráulica e Saneamento) - Escola de Engenharia de Så Carlos, 1980.

REZENDE, R. Desempenho de um sistema de irrigação pivô central quanto a uniformidade e eficiência de aplicação de água abaixo e acima da superfície do solo. Piracicaba, 1992. 86 p. Dissertação (Mestrado) - Escola Superior de Agricultura Luiz de Queiroz, 1992.

SAAD, A.M., ALBINO, J.A.S., COLOMBO, A. Irrigação: Por que avaliar o desempenho dos equipamentos. Maquinaria Agrícola, São Paulo, n. 4, v. 2, p. 1-3, 1987.

SILVA, J.G.F. da, PEREIRA, J.R.B. Análise da uniformidade de aplicação de água em um pivô central de média pressão. In: CONGRESSO BRASILEIRO DE ENGENHARIA AGRÍCOLA, 23, Campinas-SP, 1994. Anais... Campinas-SP: Sociedade Brasileira de Engenharia Agrícola, 1994.

SILVESTRE, P. Hidráulica geral. Rio de Janeiro: Livros Técnicos e Científicos, $1979.315 \mathrm{p}$.

Ciência Rural, v. 28, n. 1, 1998. 